\title{
Family Structure and Oral Habits among Children Age 1 to 12 Years resident in lle-lfe, Nigeria
}

\author{
Oyedele $\mathrm{TA}^{1,2,3}$, Kolawole $\mathrm{KA}^{1,4,5}$, Folayan $\mathrm{MO}^{1,4,5}$, Agbaje HO ${ }^{1,5}$, Oziegbe EO ${ }^{1,4,5}$, Onyejaka N ${ }^{1,6}$, Chukwumah $\mathrm{NM}^{1,7}$ \\ ${ }^{1}$ Oral Habit Study Group, lle-Ife, Nigeria \\ 2Department of Surgery, Benjamin Carson, Snr, School of Medicine, Babcock University, llisan-Remo, Ogun State \\ ${ }^{3}$ Dental Department, Babcock University Teaching Hospial, Ilisan-Remo, Ogun State \\ ${ }^{4}$ Department of Child Dental Health, Obafemi Awolowo University Teaching Hospitals' Complex, lle-Ife, Nigeria \\ ${ }^{5}$ Department of Child Dental Health, Obafemi Awolowo University, Ile-Ife, Nigeria \\ ${ }^{6}$ University of Nigeria, Enugu \\ ${ }^{7}$ University of Benin Teaching Hospital, Benin-City Edo State
}

Received for publication: January 18, 2017 Accepted: July 23, 2017

\section{Correspondence to:}

Titus Ayodeji Oyedele; E-mail: ayotitus4christ@gmail. com; +234 7062398941

E-mail addresses: KAK: kikelomokolawole@gmail.com MOF: toyinukpong@yahoo.co.uk HAO: kimex10@yahoo.com

EO0: elioziegbe@yahoo.com NKO: nnekaonyejaka@yahoo.com NMC: nnechukwumah@yahoo.com

\begin{abstract}
Oral habits are repetitive actions that are done automatically. These behaviours are started and stopped spontaneously with or without deleterious effect on the developing occlusion. Aim: To explore the family related factors associated with oral habits in children resident in sub-urban Nigeria. Methods: A cross sectional study utilizing a household survey to recruit 992 1year to 12-year-olds. Information collected using a structured questionnaire included gender, family structure (parenting structure, birth rank, number of siblings, socioeconomic status) and types of non-nutritive habits. The association between family structures related variables and presence of non-nutritive oral habits was determined using Chi square. Logistic regression was used to determine the predictors of presence of oral habits. Results: There was no significant association between the prevalence of oral habits and parenting structure $(p=0.52)$, birth rank $(p=0.50)$ and socioeconomic status $(p=0.14)$. However, the association between oral habits prevalence and number of siblings the child had was significant $(\mathrm{p}=0.03)$. The odds of having a non-nutritive oral habit reduced insignificantly for those from middle (AOR: $0.67 ; 95 \%$ Cl: 0.42-1.08) and low (AOR: 0.96; 95\% Cl: 0.59-1.55) socioeconomic class when compared with those with high socioeconomic status; and for last born and only children (AOR: 0.94; 95\% Cl: 0.56-1.60) and children with 2-4 siblings (AOR: 0.62; 95\% Cl: 0.36-1.09) when compared with those that have more than 4 siblings. The odds were higher for children who were living with single parents or guardians (AOR: $1.41 ; 95 \% \mathrm{Cl}: 0.76-2.59 ; \mathrm{p}=0.27$ ) and for males (AOR: $1.21 ; 95 \% \mathrm{Cl}: 0.82-1.78$ ). Conclusion: The study was unable to identify a significant family related predictor of presence of non-nutritive oral habits in the study population though a number of these factors increased the odds of having the habits. There is need to explore if specific family factors are associated with the presence of specific non-nutritive habits in this group of children.
\end{abstract}

\section{Introduction}

An oral habit is a repetitive action done automatically ${ }^{1}$. These repetitive behaviours are common in the infantile period. Most of them are started and finished spontaneously ${ }^{2}$. Oral habits are often associated with the stimulation of the mouth that is also a source of relief in passion and anxiety for both children and adults ${ }^{3}$. Stimulation of this region with the tongue, finger or nail can be a palliative action for anxiety, hunger fear and stress ${ }^{3}$. 
A few non-nutritive habits have been associated with psychosocial disorders. Bruxism, also known as tooth grinding, has been associated with psychosocial distress ${ }^{4}$ although bruxism in children below 6 years and sleep bruxism may not be related to any significant psychological traits ${ }^{5,6}$. Wake clenching has however been associated with a number of psychopathological symptoms ${ }^{6}$.

One of the most common repetitive oral behaviours in infantile period is digit sucking ${ }^{1}$. Sucking reflex is one of the first complex patterns of behaviour in infant and appears around the 29 weeks of age in the utero ${ }^{7}$. Digit sucking is naturally developed in $89 \%$ of infants in the second month of life and in $100 \%$ of them by the first year of age $e^{1,7}$. The frequency of engaging in this habit decreases as age increases, and most of the time; it is stopped by the age of 4 years ${ }^{1,8}$. However, a few children persist with the habit well into adolescence ${ }^{1}$.

Various factors have been associated with thumb sucking. Parental educational status is one of such factors with a greater association demonstrated between thumb sucking and children whose fathers had a low level of schooling 9 . Children with working mothers also have greater tendencies to develop sucking habits [digit, lip and tongue sucking] since the children must compete with other siblings for the mother's limited time and attention ${ }^{10-13}$. The birth position is another with the youngest child in the family reported as having greater prevalence of thumb sucking ${ }^{14}$.

Very little is known about the effect of family various structures and the reason why non-nutritive oral habits persist in children beyond the accepted periods. Prior studies had suggested that the duration of breastfeeding was inversely related to the age of pacifier use persistence ${ }^{15}$ and Jahanbin et al. ${ }^{16}$ also showed that factors associated with family structure were associated with prolonged persistence of a non-nutritive oral habit. The family may be a significant influencing factor knowing that families influence the socialisation process of children ${ }^{17}$. Family related factors could also produce continuous psychosocial distress that may inform the acquisition of non-nutritive oral habits after the preschool years or persistence of these oral habits. Family related factors that could cause psychological stress to the child include the socioeconomic status ${ }^{18}$, the birth rank $^{19}$, living with both parents, single parents or guardians ${ }^{20}$ and the size of the family ${ }^{21}$.

This study was designed to generate information on family related factors that are associated with presence of non-nutritive oral habits in children 1 year and 12-year resident in a sub-urban region in Nigeria. Specifically, it explored the association between the child's family socio-economic status, number of siblings, birth rank, the parental status (living with single parent, step parents, guardian or both parents) and the presence of non-nutritive sucking habits (finger sucking, tongue sucking, tongue thrusting, lip sucking, nail biting, object biting and bruxism).

\section{Materials and Methods}

\section{Study design}

This study is part of a larger study conducted to determine the relationship between non-nutritive oral habits and dental caries.
The study was conducted in Ife Central Local Government Area (LGA) of Osun State, a sub-urban population in the Southwest region of Nigeria. The estimated population of the LGA is put at 96,580 based on 2006 census. The primary study generated a cross sectional data utilizing a household survey over a period of six months - August 2013 to February 2014. A household survey was conducted in view of the fact that not all children in Nigeria are in school. It was estimated that $40 \%$ of primary school aged children and $60 \%$ of secondary school aged children were out of $\mathrm{school}^{22}$. It was more apt for recruiting a representative sample of the community. Parts of the primary data had been published ${ }^{23,24}$.

\section{Study population}

The participants were recruited from the National Population Enumeration sites in the LGA. The enumeration sites were the same used for the 2010 National ANC Sero-sentinel Survey and the 2012 National adolescent reproductive health survey. The study recruited children 6 months to 12-year-old whose legal guardians gave consent for study participation and who were present at home during the time of collecting this data.

\section{Sample size}

Sample size was calculated using Leslie Fischer's formula ${ }^{25}$ for study population greater than 10,000 . The sample size was determined using a prevalence of $34.1 \%$ based on the outcome of the study by Quashie-Williams et al. ${ }^{26}$ on the prevalence of oral habits among a group of children in Nigeria. It would be necessary to examine 1,011 children to be able to identify 345 children with oral habits. The sample size was rounded to 1,200 to include a $10 \%$ study participation refusal rate. However, for this study, the data of 992 children age 1 year to 12 years was extracted for analysis.

\section{Sampling technique}

Participants were recruited used a multistage sampling procedure.

Stage 1 involved the random selection of 12 out of the 25 enumeration areas within the Ife Central LGA. Stage 2 involved the selection of eligible household within the enumeration sites for the survey. At each of the enumeration sites, every third household on each street was considered eligible for study participant recruitment. Stage 3 involved the selection of actual respondent for interview and oral examination. Only one eligible child in each household participated in the study. Alternative sexes and age range identified for study recruitment were selected to participate in each consecutive household. Study participant recruitment continued in the enumeration site until the study sample per each data collector was reached. More details of this sampling technique has been reported by Folayan et al. ${ }^{23}$.

\section{Data collection tool}

The data was collected using interviewer administered structured questionnaire which were administered by experienced field workers who were trained on this study protocol. The field supervisor reviewed the questionnaires within 24 hours of data collection and any problems encountered were addressed in the field. 
The questionnaire asked details on the family structure of the child. These include socioeconomic status, birth rank, number of siblings, parenting structure (living with single parent, step parents, both parents, guardian), and types of oral habit(s) child engaged in if any (digit sucking, tongue sucking, tongue thrusting, lip sucking, nail biting, object biting, bruxism).

Socio-economic status for the purpose of this study was obtained through a scoring index combining the mother's level of education with the occupation of the father. It used an adapted version of the socio-economic status index developed by Olusanya et al. ${ }^{27}$ and previously used by Folayan et al. ${ }^{28,29}$ for studies assessing impact of socioeconomic status on oral health of children in Nigeria. The mother's level of education was classified as 'no formal education, Quranic and primary school education' were scored 2; secondary school education scored as 1; and tertiary education scored as 0 . The father's occupation was also categorised into three: Those who were civil servants or skilled professional with tertiary level of education were scored 1 ; those who were civil servants or skilled professional with secondary level of education were scored 2; and unskilled, unemployed individuals, students, and civil servants or skilled professional with primary and or Quranic level of education were scored 3. The social class was obtained through the addition of the score of the mother's level of education with that of the father's occupation. Each child was therefore allocated into social class I- V where class I referred to upper class, class II referred to upper middle class, class III referred to middle class, class IV referred to lower middle class and class $\mathrm{V}$ referred to lower class. The socioeconomic status was regrouped into three: (i) Class I and II were the high socioeconomic class, Class III was middle socioeconomic class and Class IV and $\mathrm{V}$ were the low socioeconomic class as described.

\section{Data analysis}

Statistical analysis was performed using STATA 12. For this study, the dependent variables were non-nutritive oral habits (digit sucking, tongue sucking, tongue thrusting, lip sucking, nail biting, object biting, and bruxism) and the independent variables were family structures (birth rank, number of siblings and parenting structure). Descriptive analysis was conducted for all the quantitative variables. Associations between the dependent and independent variables were determined using Chi-square. Inferential analysis was conducted to determine the significant predictors of non-nutritive oral habits using logistic regression. Adjustment was made for socioeconomic status as a possible confounder based on results of past studies showed socioeconomic status was associated with prevalence of oral habits in children ${ }^{30}$. Statistical significance was defined as $\mathrm{p}<0.05$.

Ethical consideration: Approval for this study was obtained from the Ethics and Research Committee of the Obafemi Awolowo University Teaching Hospital Ile-Ife, Nigeria (ERC/2013/07/14). Permission for the conduct of the study was sought from the Ife Central Local Government Authority. Written informed consent was obtained from the legal guardians of children who participated in the study.

\section{Results}

The mean age of the 992 study participants was $5.83 \pm$ (3.15) years. Table 1 highlights the profile of the study participants. Children between the ages of 3 years and 6 years accounted for $43.3 \%$ of the study participants. Also, $41.5 \%$ of the respondents were from the middle socioeconomic class. Of the 992 study participants, $129(13.0 \%)$ had one or more oral habits and 59 $(45.7 \%)$ of those with oral habits were between the ages of 1 year and 4 years. In addition, $117(11.8 \%)$ children had one oral habit, $11(1.1 \%)$ had two oral habits and $1(0.1 \%)$ had three oral habits.

Table 1 shows the socioeconomic status of the children with and without oral habit: $48(37.2 \%)$ of children with oral habit were from the middle socioeconomic class, 45 (34.9\%) were from low socioeconomic class and 36 (27.9\%) were from high socioeconomic status. There was no statistically significant association between the prevalence of oral habits and socioeconomic status $(p=0.29)$.

Table 1 - Profile of children resident in sub-urban Nigeria with non-nutritive oral habits $(\mathrm{N}=992)$.

\begin{tabular}{|c|c|c|c|c|c|}
\hline Variable & Oral habit & & & & \\
\hline $\begin{array}{l}\begin{array}{l}\text { Age } \\
\text { (years) }\end{array} \\
\end{array}$ & Absent $N=863 n(\%)$ & $\begin{array}{l}\text { One habit present } \mathrm{N}=117 \\
\mathrm{n}(\%)\end{array}$ & $\begin{array}{c}\text { Two habits present } \mathrm{N}=11 \\
\mathrm{n}(\%)\end{array}$ & $\begin{array}{c}\text { Three habits present } \mathrm{N}=1 \\
\mathrm{n}(\%)\end{array}$ & Total $\mathrm{N}=992 \mathrm{~N}(\%)$ \\
\hline 1 & $55(6.4)$ & $14(12.0)$ & $3(27.3)$ & - & $72(7.3)$ \\
\hline 2 & $83(9.6)$ & $12(10.3)$ & - & - & $95(9.6)$ \\
\hline 3 & $108(12.5)$ & $13(10.2)$ & $1(9.1)$ & - & $122(12.3)$ \\
\hline 4 & $86(10.0)$ & $15(12.8)$ & $1(9.1)$ & - & $102(10.3)$ \\
\hline 5 & $96(11.1)$ & $9(7.7)$ & $1(9.1)$ & - & $106(10.7)$ \\
\hline 6 & $90(10.4)$ & $10(8.5)$ & - & - & $100(10.1)$ \\
\hline 7 & $61(7.1)$ & $9(7.7)$ & $2(18.2)$ & - & $72(7.3)$ \\
\hline 8 & $72(8.3)$ & $11(9.4)$ & $2(18.2)$ & - & $85(8.6)$ \\
\hline 9 & $64(7.4)$ & $4(3.4)$ & - & - & $68(6.9)$ \\
\hline 10 & $70(8.1)$ & $10(8.5)$ & $1(9.1)$ & $1(100.0)$ & $82(8.3)$ \\
\hline 11 & $46(5.3)$ & $5(4.3)$ & - & - & $51(5.1)$ \\
\hline 12 & $32(3.7)$ & $5(4.3)$ & - & - & $37(3.7)$ \\
\hline \multicolumn{6}{|c|}{ Socioeconomic status } \\
\hline High & $203(23.5)$ & $33(28.2)$ & $3(27.3)$ & - & $239(24.1)$ \\
\hline Middle & $382(44.3)$ & $43(36.8)$ & $4(36.4)$ & $1(100.0)$ & $430(43.3)$ \\
\hline Low & $277(32.1)$ & $41(35.0)$ & $4(36.4)$ & - & $322(32.5)$ \\
\hline Missing & $1(0.1)$ & - & - & - & $1(0.1)$ \\
\hline
\end{tabular}


Table 2 shows the distribution of study participants by family structure and oral habit. Of the 129 study participants with oral habits, $62(48.1 \%)$ were first born, $89(69.0 \%)$ had 2-4 siblings and $111(86.0 \%)$ lived with both parents. There was no significant association between the prevalence of oral habit and parenting structure $\left(\mathrm{X}^{2}=1.78, \mathrm{P}=0.18\right)$ and birth rank $\left(\mathrm{X}^{2}=1.61\right.$, $\mathrm{P}=0.45)$. However, there was a significant association found between oral habit and number of siblings $\left(\mathrm{X}^{2}=4.77, \mathrm{P}=0.03\right)$, children with 2-4 sibling have higher probability of developing oral habits.

Table 2 - Distribution of children resident in sub-urban Nigeria with non-nutritive oral habits by family structure and oral habit $(\mathrm{N}=129)$.

\begin{tabular}{|c|c|c|c|c|c|}
\hline \multirow[b]{2}{*}{ Variables } & \multicolumn{5}{|l|}{ Oral habit } \\
\hline & $\begin{array}{c}\text { Present } \\
N=129 \\
n(\%)\end{array}$ & $\begin{array}{c}\text { Absent } \\
\mathrm{N}=863 \\
\mathrm{n}(\%)\end{array}$ & $\begin{array}{c}\text { Total } \\
\mathrm{N}=992 \\
\mathrm{n}(\%)\end{array}$ & $\mathrm{X}^{2}$ & P value \\
\hline \multicolumn{6}{|l|}{ Parenting structure } \\
\hline Both parents & $111(86.0 \%)$ & $773(89.6 \%)$ & $884(89.1 \%)$ & & \\
\hline Other parenting structure & $15(11.6 \%)$ & $70(8.1 \%)$ & $85(8.6 \%)$ & & \\
\hline \multicolumn{6}{|l|}{ Number of siblings } \\
\hline 1 & $29(22.5 \%)$ & $128(14.8 \%)$ & $157(15.8 \%)$ & & \\
\hline $2-4$ & $89(69.0 \%)$ & $663(76.8 \%)$ & $752(75.8 \%)$ & 4.77 & 0.03 \\
\hline$>4$ & $11(8.5 \%)$ & $66(7.6 \%)$ & $77(7.8 \%)$ & & \\
\hline \multicolumn{6}{|l|}{ Birth rank } \\
\hline First born & $62(48.1 \%)$ & $369(42.8 \%)$ & $431(43.4 \% \%)$ & & \\
\hline $\begin{array}{l}\text { Last born and } \\
\text { the only child }\end{array}$ & $32(28.8 \%)$ & $240(27.8 \%)$ & $272(27.4 \% \%)$ & 1.61 & 0.45 \\
\hline Others & $32(28.8 \%)$ & $245(28.4 \%)$ & $277(27.9 \%)$ & & \\
\hline
\end{tabular}

Table 3 shows the outcome of the multivariate logistic regression to determine the predictors of presence of oral habits. Parenting structure, number of sibling and birth rank was not significant predictor of presence of non-nutritive oral habits. Children who lived with other parents (single parents, step parent or guardians) had insignificantly increased odds of having an oral habit (AOR: 1.41; 95\% CI: 0.76-2.59; $\mathrm{p}=0.27$ ) when compared with children who were living with both parents. Also, children who were last born and only child (AOR: 0.94 ; 95\% CI: $0.56-$ $1.60 ; p=0.83$ ) and who had other birth ranks (AOR: 0.89; 95\% CI: $0.51-1.56 ; p=0.70$ ) had insignificantly reduced odds of having oral habits when compared with children who were first born. In addition, children with 2 to 4 siblings (AOR: 0.62; 95\% CI: 0.36 $1.09 ; \mathrm{p}=0.10)$ and greater than 4 siblings (AOR: $0.79 ; 95 \% \mathrm{CI}$ : $0.31-2.00 ; p=0.62$ ) had insignificant increased odds of having an oral habits when compared with children who had one or no siblings.

Table 3 - Logistic regression to determine predictors of presence of oral habits $(\mathrm{N}=992)$.

\begin{tabular}{|c|c|c|c|c|c|}
\hline \multirow[b]{2}{*}{ Variables } & Oral habit & & Adjusted OR & $95 \%$ C.I & $P$ value \\
\hline & $\begin{array}{c}\text { Absent } \\
\mathrm{N}=863 \\
\mathrm{n} \%\end{array}$ & $\begin{array}{c}\text { Present } \\
\mathrm{N}=129 \\
\mathrm{n} \%\end{array}$ & & & \\
\hline \multicolumn{6}{|l|}{ Sex } \\
\hline Female & $425(49.2)$ & $59(45.7)$ & 1 & - & - \\
\hline Male & $438(50.8)$ & $70(54.3)$ & 1.21 & $0.82-1.78$ & 0.33 \\
\hline \multicolumn{6}{|l|}{ Socioeconomic status } \\
\hline High & $203(23.5)$ & $36(27.9)$ & 1 & - & - \\
\hline Middle & $382(44.3)$ & $48(37.2)$ & 0.67 & $0.42-1.08$ & 0.10 \\
\hline Low & $277(32.1)$ & $45(34.9)$ & 0.96 & $0.59-1.55$ & 0.86 \\
\hline \multicolumn{6}{|l|}{ Birth rank } \\
\hline First born & $369(42.8)$ & $62(49.2)$ & 1 & - & - \\
\hline Last born and only child & $240(27.8)$ & $32(25.4)$ & 0.94 & $0.56-1.60$ & 0.83 \\
\hline Others & $245(28.4)$ & $32(25.5)$ & 0.89 & $0.51-1.56$ & 0.70 \\
\hline \multicolumn{6}{|l|}{ Number of siblings } \\
\hline $0-1$ & $128(14.9)$ & $29(22.5)$ & 1 & - & - \\
\hline $2-4$ & $663(77.4)$ & $89(69.0)$ & 0.62 & $0.36-1.09$ & 0.10 \\
\hline$>4$ & $66(7.7)$ & $11(8.5)$ & 0.79 & $0.31-2.00$ & 0.62 \\
\hline \multicolumn{6}{|l|}{ Parenting structure } \\
\hline Both parents & $773(91.7)$ & $111(86.4)$ & 1 & - & - \\
\hline Other parenting structure & $70(8.3)$ & $15(11.6)$ & 1.41 & $0.76-2.59$ & 0.27 \\
\hline
\end{tabular}




\section{Discussion}

This study was unable to find any significant association between presence of non-nutritive oral habits, parenting structure, birth rank, number of siblings and the socioeconomic status of children resident in Ile-Ife. However, the odds of having a non-nutritive oral habit reduced for males when compared to female, for those in the middle and low socioeconomic class when compared to those in the high socioeconomic class, for last born when compared with first born children and for children who were living with single parents or guardians when compared with those living with both parents. We also found that children with other birth ranks (not last borns) and those with more than one sibling were more likely to have a non-nutritive oral habit.

The findings of this study differed from findings of some prior studies. For example, Jahanbin et al. ${ }^{16}$ showed that the child's birth rank, number of siblings and parents' education level were significant factors associated with presence of non-nutritive oral habits in 7-year-old Iranian children unlike what we found in this study. Fernandes et al. ${ }^{31}$ on the other hand, showed that children of mothers with lower educational status were less likely to have non-nutritive oral habits similar to our observation that the prevalence of non-nutritive oral habits reduced with lowering socio-economic status. Our observation however, did not reach statistical significance.

There are a few studies that have identified family structure related factors associated with presence of non-nutritive oral habits in older children. Williams et al. ${ }^{32}$ showed that more undergraduates not living with both parents bite their nails. Also, Murrieta et al. ${ }^{33}$ noted that primary school children who lived with both parents were more likely to be emotionally stable and therefore adopt less non-nutritive oral habits. Quashie-Williams et al. ${ }^{34}$ who studied the prevalence of non-nutritive oral habits in children 4-15 years, found that significantly more children from higher socioeconomic status had non-nutritive oral habits. They however did not study the relationship of other family related factors with the presence of non-nutritive oral habits. Our study evaluated the role of multiple family related factors on the presence of non-nutritive sucking habits in children and we found no significantly associated family factor.

This study was however limited in its ability to assess the effect of family related factors on the presence of specific nonnutritive oral habits because the small number of children with specific non-nutritive oral habits made it difficult to do these subanalyses. It would have been useful to identify if there are specific family related variables that are associated with the presence of specific non-nutritive oral habits. Despite this limitation, the study was able to identify that parenting structure, birth rank, number of siblings and the socioeconomic status did not increase the chances of children in the study environment indulging in non-nutritive oral habits. Also, the use of a household survey for study participants' recruitment in a country where a significant number of children are out of school $^{22}$ makes the finding of this study generalisable to the study population. Further studies are needed to explore how family related factors are associated with presence of specific non-nutritive oral habits in children.

\section{Conclusion}

The sex, socioeconomic status, birth rank, number of siblings and the parenting structure of children resident in Ile-Ife, Nigeria were not significant predictors of presence of non-nutritive oral habits in children. There is a need to further explore if specific family factors are associated with the presence of specific nonnutritive habits in children 1 year old and older.

\section{Authors' contributions}

TAO conceived the idea, designed and made substantial contributions to acquisition, analysis, and interpretation of the result and manuscript right up. MOF, KAK, EOO, NMC, NO made substantial contribution to the design, acquisition, analysis and interpretation and manuscript right up. All authors agreed to the final version of the manuscript.

\section{Competing interest}

The authors declare that there are no competing interests.

\section{Acknowledgement}

The authors acknowledge the parents and children that participated in the study.

\section{References}

1. Maguire JA. The evaluation and treatment of pediatric oral habits. Dental Clin North Am. 2000 Jul;44(3):659-69, vii.

2. Shahraki N, Yassaei S, Moghadam MG. Abnormal oral habits: a review. J Dent Oral Hyg. 2012 May;4(2):12-5. Doi: 10.5897/JDOH12.001.

3. Bear PN, Lestor M. The thumb, the pacifier, the erupting tooth and a beautiful smile. J Pedod. 1987 Whinter;11(2):115-9.

4. Funch DP, Gale EN. Factors associated with nocturnal bruxism and its treatment. J Behav Med. 1980 Dec;3(4):385-7.

5. Kuch EV, Till MJ, Messer LB. Bruxing and non-bruxing children: a comparison of their personality traits. Pediatr Dent. 1979 Sep;1(3):182-7.

6. Manfredini D, Lobbezoo F. Role of psychosocial factors in the etiology of bruxism. J Orofac Pain. 2009 Spring;23(2):153-66.

7. Rani MS. Synopsis of orthodontics. 2nd ed. Delhi: All India publisher and Distributors; 1998. p. 179-200.

8. Larson EF. The prevalence and aetiology of prolonged dummy and finger-sucking habits. Eur J Orthod. 1985 Aug; 7(3):172-6.

9. Gupta BI, Bhavna G, Indushekar KR. Childhood thumb sucking habit: the burden of a preventable problem! J Dent Med Sci. 2012 Jun;2(1):1-4.

10. Adair SM. Pacifier use in children: a review of recent literature. Pediatr Dent. 2003 Sep-Oct;25(5):449-58.

11. Farsi NM, Salama FS. Sucking habits in Saudi children: prevalence, contributing factors and effects on the primary dentition. Pediatr Dent. 1997 Jan-Feb;19(1):28-33.

12. Turgeon-O'Brien H, Lachapelle D, Gagnon PF, Larocque I, MaheuRobert LF. Nutritive and non-nutritive sucking habits: a review. ASDC J Dent Child. 1996 Sep-Oct;63(5):321-7.

13. Warren JJ, Bishara SE. Duration of nutritive and non-nutritive sucking behaviors and their effects on the dental arches in the primary dentition. Am J Orthod Dento-facial Orthop. 2002 Apr;121(4):347-56.

14. Rajchanovska D, Zafirova-Ivanovska B. Oral habits among preelementary children in Bitola. Prilozi. 2012;33(1):157-69.

15. Telles FB, Ferreira RI, MagalhãesLdo N, Scavone-Junior H. Effect 
of breast- and bottle-feeding duration on the age of pacifier use persistence. Braz Oral Res. 2009 Oct-Dec;23(4):432-8.

16. Jahanbin A, Mokhber N, Jabbarimani A. Association between sociodemographic factors and nutritive and non-nutritive sucking habits among Iranian girls. East Mediterr Health J. 2010 Nov;16(11):1143-7.

17. Richards MH, Gitelson IB, Peterson AC, Hartig AL. Adolescent personality in girls and boys: The role of mothers and fathers. Psychol Women Quart. $1991 \mathrm{Mar} ; 15(1): 65-81$.

18. Chen E. Why socioeconomic status affects the health of children: a psychosocial perspective. Curr Direct Psychol Sci. 2004 jun; 13(3):1125 .

19. Dohrenwend BS, Dohrenwend BP. Stress situations, birth order, and psychological symptoms. J Abnormal Psychology. 1966 Jun;71(3):21523.

20. Falana BA, Bada FO, Ayodele CJ. Single-parent family structure, psychological, social and cognitive development of children in Ekiti State. J Educ Develop Psychol. 2012 Aug;2(2):158-64. DOI: 10.5539/ jedp.v2n2p158.

21. Oyerinde 00 . The impact of family structure, parental practices and family size on children's academic performance. Nig School Health J. 2001;13(2):160-8.

22. UNICEF. Nigeria-The children Education. 2005 [Cited 2014 Dec 20]. Available from: www.unicef/org/nigeria/children.

23. Folayan MO, Kolawole KA, Oyedele TA, Chukwumah NM, Onyejaka $\mathrm{N}$, Agbaje $\mathrm{H}$, et al. Erratum: Association between knowledge of caries preventive practices, preventive oral health habits of parents and children and caries experience in children resident in sub-urban Nigeria. BMC Oral Health. 2015 May 20;15:62. doi: 10.1186/s12903-015-0044-4.

24. Folayan MO, Kolawole KA, Oziegbe EO, Oyedele TA, Oshomoji OV, Chukwumah et al. Prevalence and early childhood caries risk indicators in preschool children in suburban Nigeria. BMC Oral Health. 2015 Jun 30;15:72. doi: 10.1186/s12903-015-0058-y.

25. Araoye MO. Research methodology with statistics for health and social science. Ilorin: Nathadex Publisher; 2003. p.115-9.

26. Quashie-Williams R, daCosta OO, Isiekwe MC. Oral habits, prevalence and effects on occlusion of 4-15 year old school children in Lagos, Nigeria. Niger Postgrad Med J. 2010 Jun;17(2):113-7.

27. Olusanya $\mathrm{O}$, Okpere $\mathrm{O}$, Ezimokhai $\mathrm{M}$. The importance of social class in voluntary fertility control in developing country. West Afr J Med. 1985;4(4):205-12

28. Folayan MO, Otuyemi OD. Reliability and validity of a short form of the dental subscale of the child fear survey schedule used in Nigerian children population. Niger J Med. 2002 Oct-Dec;11(4):161-3.

29. Folayan $\mathrm{MO}$, Idehen $\mathrm{EE}$, Ufomata $\mathrm{D}$. The effect of sociodemographic factors on dental anxiety in children seen in a suburban Nigerian hospital. Int J Peadiatr Dent. 2003 Jan;13(1):20-6.

30. Taylor VJ, Cook PA. The prevalence of dummy sucking in two socioeconomic groups in Leeds [abstract 72]. J Dent Res. 1989; 68:567.

31. Fernandes IB, Pereira TS, Figueiredo de Carvalho MF, Ramos-Jorge J, Marques LS, Ramos-Jorge LM. Non-nutritive sucking habits after three years of age: A case-control study. J Indian Soc Pedod Prev Dent. 2015 Jan-Mar;33(1):19-24. doi: 10.4103/0970-4388.148965.

32. Williams TI, Rose R, Chisholm S. What is the function of nail biting: an analog assessment study. Behav Res Ther. 2007 May;45(5):989-95.

33. Murrieta JF, Hernández D, Linares $\mathrm{C}$, Gonzáles M, Juárez L, Montaño V. Parafunctional oral habits and its relationship with family structure in a Mexican preschoolers group. J Oral Res. 2014;3(1):29-35.

34. Quashie-Williams R, Dacosta OO, Isiekwe MC. The prevalence of oral habits among 4 to 15 year old school children in Lagos. Nig J Health Biomed Sci. 2007;6(1):78-82. 